\title{
Análise dos resultados de um estudo de demanda para proposição de uma especialização técnica em saúde do idoso
}

\section{Analysis of the results of a demand study for proposing a technical specialization in elderly health}

Recebido: 08/02/0020 | Revisado: 21/12/2020 | Aceito: 01/02/2021 | Publicado: 17/05/2021

Isabella Cristina Moraes Campos ORCID: https://orcid.org/0000-0001-8909264X

Instituto Federal Sudeste de Minas Gerais Campus São João del-Rei

E-mail:

isabella.campos@ifsudestemg.edu.br

Isabel Cristina Adão Schiavon

ORCID: http://orcid.org/0000-0003-1679985X

Instituto Federal Sudeste de Minas Gerais Campus São João del-Rei

E-mail: isabel.schiavon@ifsudestemg.edu.br

\section{Vaneska Ribeiro Perfeito Santos}

ORCID: https://orcid.org/0000-0001-88668619

Instituto Federal Sudeste de Minas Gerais -

Campus São João del-Rei

E-mail:

vaneska.perfeito@ifsudestemg.edu.br

\section{Lilian do Nascimento}

ORCID: https://orcid.org/0000-0002-40532891

Instituto Federal Sudeste de Minas Gerais Campus São João del-Rei E-mail:

lilian.nascimento@ifsudestemg.edu.br

Suzana Vale Rodrigues

ORCID: https://orcid.org/0000-0003-05778658

Instituto Federal Sudeste de Minas Gerais Campus São João del-Rei

E-mail:

suzana.rodrigues@ifsudestemg.edu.br

Como citar: CAMPOS, I. C. M.; SCHIAVON, I. C. A.; SANTOS, V. R. P.; NASCIMENTO, L. do; RODRIGUES, S. V. Análise dos resultados de um estudo de demanda para proposição de uma especialização técnica em saúde do idoso. Revista Brasileira da Educação Profissional e Tecnológica, [S.I.], v. 1, n. 20, p 1-17. e10874. maio. 2021. ISSN 24471801.

This work is licensed under a Creative Commons Attribution 4.0 Unported License.

\section{Resumo}

Cada vez mais o envelhecimento da população requer técnicos de enfermagem capacitados para assistirem as necessidades dos idosos. O objetivo foi apresentar os resultados de um estudo de demanda para verificação da viabilidade de proposição de uma Especialização Técnica em Saúde do Idoso, em uma instituição federal de ensino de Minas Gerais. A amostra foi composta por 240 técnicos de enfermagem e discentes de um curso Técnico em Enfermagem. A coleta de dados foi entre novembro e dezembro de 2019. A análise de dados foi realizada no Statistical Package for the Social Sciences for Windows 20. Foi analisado o perfil sociodemográfico e ocupacional dos participantes interessados no curso, bem como a melhor maneira de ofertá-lo. Os resultados evidenciaram a aceitação da especialização dentre os participantes do estudo de demanda.

Palavras-chave: Educação Profissionalizante. Enfermagem. Saúde do Idoso. Técnicos de Enfermagem. Educação Continuada.

\section{Abstract}

The aging of the population increasingly requires trained nursing technicians to assist the needs of the elderly. The objective was to present the results of a demand study to verify the feasibility of proposing a Technical Specialization in Health of the Elderly, at a federal educational institution in Minas Gerais. The sample consisted of 240 nursing technicians and students of a Nursing Technician course. Data collection took place between November and December 2019. Data analysis was performed in the Statistical Package for the Social Sciences for Windows 20. The sociodemographic and occupational profile of the participants interested in the course was analyzed, as well as the best way to offer them. it. The results showed the acceptance of specialization among the participants in the demand study.

Keywords: Education, Professional. Nursing. Health of the Elderly. Licensed Practical Nurses. Education, Continuing. 


\section{INTRODUÇÃO}

O envelhecimento da população é uma tendência global e, de acordo com a Organização Mundial de Saúde (OMS), o número de pessoas acima de 60 anos deve chegar a $22 \%$ da população mundial até 2050 , o equivalente a dois bilhões de pessoas, mais que o dobro dos 900 milhões de indivíduos nessa faixa etária em 2015. Os idosos representarão um quinto da população do planeta. Todavia, os atuais sistemas de saúde não estão preparados para atendê-los de forma adequada (OMS, 2018).

No Brasil, a população também envelhece de forma rápida e intensa. Dados do Instituto Brasileiro de Geografia e Estatística (IBGE) revelaram uma população idosa composta por 29.374 milhões de pessoas, o que representa $14,3 \%$ da população total do país. A expectativa de vida, em 2016, para ambos os sexos, aumentou para 75,72 anos, sendo 79,31 anos para as mulheres e 72,18 anos para os homens (BRASIL, 2019).

Estima-se que, no ano de 2030, o Brasil terá a sexta população mundial de idosos. Em 2025, já serão 35 milhões, com o total de indivíduos com mais de 60 anos dobrando até 2050 , de $9,5 \%$ para $21,8 \%$ da população, e ultrapassando 40 milhões de pessoas. As estimativas ainda apontam que, em 2039, o número de idosos será maior que o de crianças de zero a 14 anos (IBGE, 2016).

A transição demográfica, as mudanças sociais e a melhoria das condições de vida da população resultam em novos desafios a serem enfrentados no cuidado à população idosa, dirigidos principalmente às políticas de saúde, de assistência social e de previdência social (BRASIL, 2019). Acrescenta-se a esses desafios o da capacitação dos profissionais que atuarão junto à população em processo de envelhecimento.

A Política Nacional de Saúde da Pessoa Idosa, instituída pela Portaria oㅡ 2.528/2006, estabeleceu que o cuidado destinado aos idosos requer uma abordagem global, interdisciplinar e multidimensional. Deve considerar a interação entre fatores físicos, psicológicos e sociais que influenciam sua saúde, além do ambiente em que estão inseridos. Essas intervenções precisam ser realizadas e orientadas visando à promoção da autonomia e independência do idoso, estimulando-o, quando possível, para o autocuidado. Além disso, estabelece a necessidade de provimento de recursos capazes de assegurar qualidade da atenção à saúde da pessoa idosa e a formação e educação permanente dos profissionais de saúde, gestores e usuários do Sistema Único de Saúde (SUS) (BRASIL, 2006).

A equipe de Enfermagem constitui o maior contingente de profissionais de saúde e a maior parte dessa equipe é composta por profissionais de nível médio. Dessa forma, a procura por cursos nessa área é grande. No Brasil, são 2.322.327 profissionais de Enfermagem, sendo 1.333.160 técnicos (57,4\%) (COFEN, 2020). O técnico de enfermagem, regulamentado pela Lei 7.498/86, integra a equipe de saúde, sob a supervisão do Enfermeiro (BRASIL, 1986). Deve compreender e atuar de acordo com os princípios do SUS, valorizar a integralidade e o direito do indivíduo à assistência em qualquer nível da atenção à saúde, trabalhar em equipe multiprofissional e interdisciplinar na compreensão de fenômenos que envolvam o processo saúde-doença e adotar a comunicação, a liderança e a tomada de decisão. 
A formação de técnicos de enfermagem cidadãos, comprometidos com uma prática profissional humanizada, com vistas ao cuidado dos idosos fundamentado em conhecimentos técnico-científicos, éticos, políticos e educacionais, torna-se importante. Assim, a disponibilização, para a sociedade, de profissionais aptos ao exercício de suas funções em Enfermagem, de acordo com suas competências legais e princípios éticos, frente aos cuidados com saúde e integridade da pessoa idosa, é fundamental. Sobretudo, qualificados para o trabalho em equipe interdisciplinar, reconhecendo a importância da assistência multidimensional no cuidado do idoso.

A Especialização Técnica em Saúde do Idoso é apontada pelo Catálogo Nacional de Cursos Técnicos como uma das possibilidades de formação continuada dos técnicos de enfermagem (BRASIL, 2017). Constitui-se em uma oportunidade de aprimoramento profissional e propicia novas competências àqueles que desejam especializar-se em saúde do idoso. Sua organização curricular é estabelecida de acordo com o Eixo Tecnológico de "Ambiente e Saúde", com terminalidade correspondente à qualificação profissional de nível especialista técnico.

O Técnico de Enfermagem Especialista em Saúde do Idoso será o profissional que poderá atuar junto à população idosa de maneira mais qualificada. Faz parte de suas atribuições o zelo pela integridade física do idoso, além de capacitação para realização de procedimentos de suporte básico de vida, incentivo ao autocuidado e realização de apoio a atividades de vida diária e ações de entretenimento voltadas para os idosos em hospitais, instituições de longa permanência para idosos (ILPIs), casas de repouso, clubes da terceira idade, atendimento domiciliar, dentre outros.

Diante do exposto, o objetivo deste estudo foi apresentar os resultados de um estudo de demanda para verificação da viabilidade de proposição de uma Especialização Técnica em Saúde do Idoso, em uma instituição federal de ensino de Minas Gerais. Tais dados embasaram a proposição da oferta do curso e foi analisado o perfil sociodemográfico e ocupacional dos técnicos de enfermagem interessados em realizar o curso, bem como qual seria a melhor maneira de ofertá-lo.

\section{MÉTODO}

O estudo de demanda, obrigatório na instituição de ensino para a proposição de novos cursos, embasou a oferta da Especialização Técnica em Saúde do Idoso. Foi adotada a abordagem quantitativa e consistiu em uma pesquisa de levantamento, cujo delineamento selecionado visa estudar a distribuição e as relações entre variáveis naturais relativas a pessoas ou grupos advindos de toda ou parte de uma população-alvo (SELLTIZ; WRIGHTSMAN; COOK, 2006).

Foram coletados dados primários diretamente com técnicos de enfermagem e discentes de um curso Técnico em Enfermagem, ofertado pela instituição desde 2010, que são o público-alvo da Especialização Técnica em Saúde do Idoso. A aplicação do questionário (Anexo A) visou obter dados quantitativos que pudessem ser avaliados por meio de técnicas estatísticas. O objetivo foi verificar as características sociodemográficas e ocupacionais dos interessados pela especialização e a melhor forma de ofertá-la.

O questionário foi testado em um estudo piloto e, após adequações, foi enviado para instituições de saúde e ILPIs do município da instituição de ensino e 
região impresso, por e-mail e por um link do Google Drive, de forma que a coleta pudesse ser abrangente. Das mesmas formas, foi enviado aos discentes do curso Técnico em Enfermagem. A coleta de dados ocorreu nos meses de novembro e dezembro de 2019.

A participação na pesquisa foi voluntária, os participantes não foram identificados e os dados pessoais foram mantidos em sigilo, pois não foram divulgados individualmente, mas, sim, em termos de grupo. Segundo a Resolução no 510/2016, esta pesquisa de opinião pública não precisaria ser submetida à avaliação de um Comitê de Ética em Pesquisa com Seres Humanos (BRASIL, 2016).

A análise de dados foi realizada por meio do software Statistical Package for the Social Sciences for Windows 20 (SPSS). Foi feita estatística descritiva, com cálculo de médias, desvios-padrão, porcentagens e valores mínimos e máximos para a caracterização da amostra, com a descrição das características sociodemográficas e ocupacionais dos participantes, bem como das opiniões acerca da Especialização Técnica em Saúde do Idoso.

Para a verificação das respostas sobre o interesse em realizarem o curso (sim, não e talvez) em relação às variáveis analisadas, foi empregado o Teste $t$ de Student para amostras independentes, no caso das variáveis contínuas; e o Teste Qui-Quadrado, para as variáveis categóricas. Os resultados foram apresentados em gráficos e tabelas. Os testes estatísticos inferenciais foram conduzidos adotando-se o nível de significância de $p<0,05$ (LEVIN; FOX; FORDE, 2012).

\section{RESULTADOS E DISCUSSÃO}

\subsection{PERFIL SOCIODEMOGRÁFICO E OCUPACIONAL DA AMOSTRA}

A amostra do estudo de demanda foi não probabilística por conveniência, composta por 240 técnicos de enfermagem e estudantes do curso Técnico em Enfermagem. A idade média dos participantes foi 33 anos ( $D P=9,699)$, variando entre 19 e 59 anos. A metade da amostra apresentava idade igual ou superior a 31 anos $(50 \%)$. Houve um equilíbrio entre as faixas etárias, o que sugere que o mercado de trabalho da região agregava tanto profissionais mais jovens, até 31 anos, como profissionais acima dessa idade.

Em um levantamento realizado no banco de dados do Conselho Regional de Enfermagem de Minas Gerais (COREN-MG), dentre os técnicos e enfermeiros que solicitaram a autorização para exercício da Enfermagem, a faixa etária mais prevalente foi a de menos de 30 anos, sendo $74,6 \%$ entre os enfermeiros e $45,6 \%$ entre os técnicos de enfermagem. Na faixa etária de 30 a 40 anos, o percentual de técnicos foi de $39,3 \%$. Nessa direção, os resultados expressaram a disponibilidade de pessoas relativamente jovens ingressando no mercado de trabalho em saúde em Minas Gerais (RIBEIRO et al., 2014).

Com relação ao gênero, 199 participantes eram mulheres (82,9\%) e 41 homens $(17,1 \%)$. Ressalta-se que essa diferença é histórica e característica da Enfermagem, uma profissão exercida majoritariamente por mulheres. $O$ gênero feminino acaba sendo a representação mais expressiva dos trabalhadores da 
categoria profissional e tal realidade caracteriza-se por fatores com mais aproximação sócio-histórica no exercício das atividades que envolvem o cuidar (MALAGUTTI; MIRANDA, 2011).

Quanto ao estado civil, a maioria era solteira ( $n=136 ; 57,1 \%$ ), seguida pelos(as) casados(as) ( $n=77 ; 32,4 \%$ ), separados(as) ou divorciados(as) ( $n=22$; $9,2 \%$ ) e viúvos(as) ( $n=3 ; 1,3 \%$ ). No que concerne ao nível de escolaridade, a maior parte dos participantes tinha ensino médio ( $n=196 ; 81,7 \%)$, pois concluiu $(n=211$; $87,9 \%$ ) ou estava fazendo o curso Técnico em Enfermagem ( $n=29 ; 12,1 \%)$.

A maioria dos participantes, 165 pessoas (68,8\%), residia no mesmo município da instituição de ensino e o restante morava na região ( $n=75 ; 31,2 \%)$. Em relação ao município onde realizaram o curso Técnico em Enfermagem, 218 respondentes (90,8\%) estudaram nas três instituições do município, sendo 113 egressos ou estudantes da instituição de ensino onde a proposta da oferta da especialização fora feita $(47,3 \%)$.

Dentre os que já eram técnicos de enfermagem ( $n=211 ; 87,9 \%)$, a média de tempo de conclusão do curso Técnico em Enfermagem foi de quase oito anos $(\mathrm{M}=$ 7,956 ; DP $=7,28$ ), variando entre seis meses e 33 anos. Dentre esses profissionais, $46,4 \%$ tinham até cinco anos de profissão, 25\% entre cinco e 10 anos e 13,5\% tinham 15 anos ou mais. Portanto, a amostra foi composta, em grande medida, por técnicos de enfermagem experientes e com muitos anos de atuação no mercado de trabalho.

A maior parte dos participantes relatou que estava trabalhando ( $n=214$; $89,2 \%$ ) e, dentre os 211 que já eram formados (87,9\%), 174 trabalhavam como técnicos de enfermagem (72,5\%). A maioria trabalhava em escala de plantão de $12 \times 36$ horas $(n=122 ; 54,0 \%)$ ou trabalhava diariamente $(n=69 ; 30,5 \%)$. Mais de dois terços trabalhavam no turno diurno $(n=157 ; 68,3 \%)$ e, dos 174 que atuavam como técnicos de enfermagem, 12 relataram ter mais de um emprego $(5,0 \%)$.

\subsection{ANÁLISE DO INTERESSE EM CURSAR A ESPECIALIZAÇÃO TÉCNICA EM SAÚDE DO IDOSO}

Quando questionados, 210 participantes relataram que tinham interesse na área de cuidados com a pessoa idosa (88,6\%). O campo de trabalho em saúde do idoso foi considerado como promissor para 218 pessoas $(90,8 \%)$. Em relação ao interesse em cursar a Especialização Técnica em Saúde do Idoso, 199 pessoas responderam positivamente (82,9\%), 24 assinalaram que não gostariam de cursar a especialização $(10,0 \%)$ e 17 participantes responderam que talvez fariam o curso $(7,1 \%)$.

Portanto, observa-se que a área de cuidados com os idosos foi alvo de interesse do público-alvo da Especialização Técnica em Saúde do Idoso e a rejeição ao curso foi baixa. Vale ressaltar que as pessoas que responderam "não" justificaram que se interessavam por outras áreas, que não trabalhavam mais como técnicos de enfermagem ou simplesmente que não gostavam da área de cuidados com a pessoa idosa.

Uma análise pormenorizada das justificativas das pessoas que responderam talvez à pergunta sobre o interesse pelo curso faz-se necessária. A princípio, deve-se destacar que essas pessoas não descartaram a hipótese de fazerem o curso. Isso 
pode ser notado nas justificativas apresentadas: "Caso eu consiga passar pra fazer alguma faculdade, eu optaria em fazer faculdade.", "Pelo fato do emprego ao qual estou no momento.", "Devido ao tempo e busca por outras áreas.", "Devido ao horário de trabalho.", "Falta de tempo."; "Faria mais para adquirir conhecimento, pois me identifico mais com pediatria e neonatologia.", "Terminando a graduação em Enfermagem.", "Indisponibilidade de horário." Observa-se que os motivos apresentados não desabonaram o curso em si, mas, sim, estiveram relacionados a desejos e objetivos pessoais diversos ou a compromissos que poderiam impedir essas pessoas de fazerem o curso.

As variáveis sociodemográficas e ocupacionais foram cruzadas com as respostas quanto ao interesse em cursar a especialização. A variável "idade" foi cruzada com a variável "interesse em fazer a Especialização Técnica em Saúde do Idoso" (Gráfico 1). Por meio desse cruzamento, verificou-se que não houve diferença significativa estatisticamente das idades dos participantes $(p=0,063)$. Além disso, pôde-se observar que pessoas de idades variadas se interessaram em fazer o curso. Ainda, que os mais velhos e mais experientes como técnicos de enfermagem responderam que gostariam de fazê-lo, o que correspondeu a uma indicação significativa para a oferta do curso.

Gráfico1: Relação entre as variáveis "idade" (em anos) e "interesse em fazer a Especialização Técnica em Saúde do Idoso" ( $N=240)$.

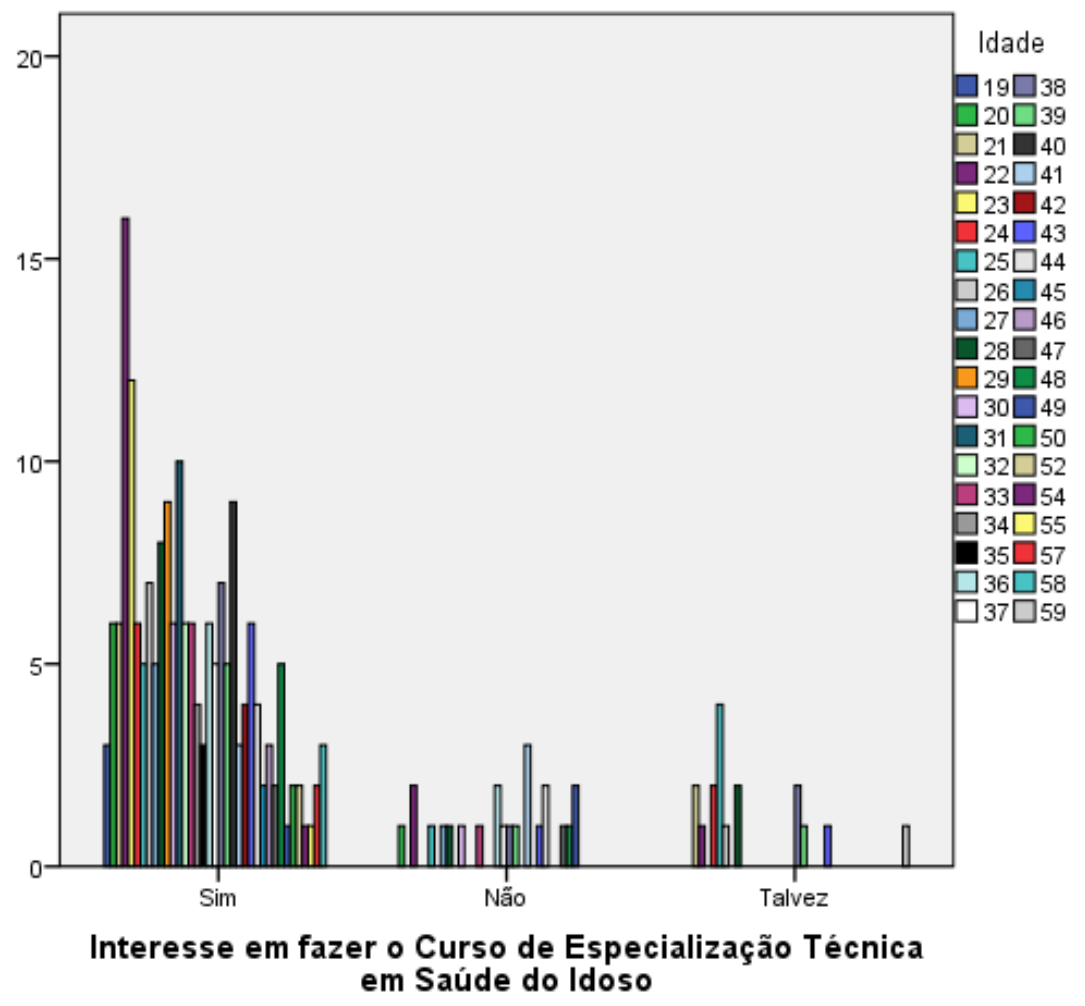

Fonte: Elaborado pelas autoras. São João del-Rei, 2020.

A variável "tempo de conclusão do curso Técnico em Enfermagem" foi cruzada com a variável "interesse em fazer a Especialização Técnica em Saúde do Idoso" (Gráfico 2). Por esse procedimento, verificou-se que o tempo de conclusão não 
foi significante estatisticamente $(p=0,122)$, mostrando que pessoas com variados tempos de profissão gostariam de fazer a especialização. Em especial, observa-se que as mais experientes mostraram interesse e eram justamente essas pessoas que mais poderiam conhecer a profissão e o mercado de trabalho em Enfermagem, o que é um importante indicativo de demanda para o curso.

Gráfico 2: Relação entre as variáveis "tempo de conclusão do curso Técnico em Enfermagem" (em anos) e "interesse em fazer a Especialização Técnica em Saúde do Idoso" $(N=240)$.

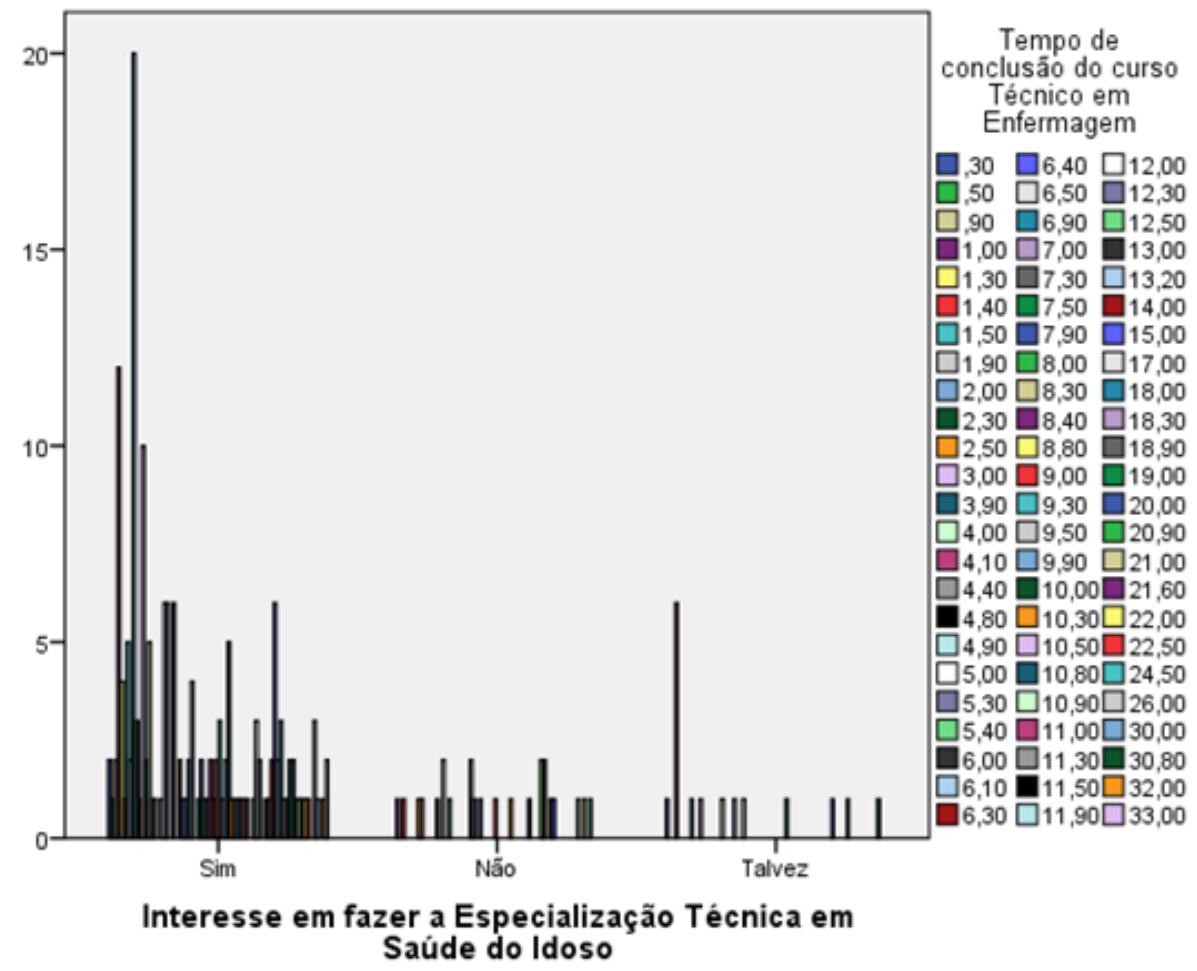

Fonte: Elaborado pelas autoras. São João del-Rei, 2020.

A Tabela 1 apresenta os resultados do cruzamento das demais variáveis, as categóricas, com o interesse em cursar a especialização.

Tabela 1: Relação entre o interesse pela Especialização Técnica em Saúde do Idoso e as variáveis sociodemográficas e ocupacionais categóricas $(N=240)$. São João del-Rei, 2020.

\begin{tabular}{|c|c|c|c|c|c|}
\hline \multirow[t]{2}{*}{ Variáveis } & \multirow[t]{2}{*}{ Categorias } & \multicolumn{3}{|c|}{ Percentual de Interesse } & \multirow[t]{2}{*}{$p$} \\
\hline & & Sim & Não & Talvez & \\
\hline Gênero & $\begin{array}{l}\text { Feminino } \\
\text { Masculino }\end{array}$ & $\begin{array}{c}166(69,2) \\
33(13,8)\end{array}$ & $\begin{array}{c}20(8,3) \\
4(1,7)\end{array}$ & $\begin{array}{c}13(5,4) \\
4(1,7)\end{array}$ & 0,765 \\
\hline Estado civil & $\begin{array}{l}\text { Solteiro } \\
\text { Casado } \\
\text { Separado/divorciado } \\
\text { Viúvo }\end{array}$ & $\begin{array}{c}116(48,7) \\
63(26,5) \\
17(7,1) \\
2(0,8)\end{array}$ & $\begin{array}{l}8(3,4) \\
11(4,6) \\
3(1,3) \\
1(0,4)\end{array}$ & $\begin{array}{l}12(5) \\
3(1,3) \\
2(0,8) \\
0\end{array}$ & 0,231 \\
\hline Escolaridade & $\begin{array}{l}\text { Ensino médio } \\
\text { Superior incompleto } \\
\text { Superior completo }\end{array}$ & $\begin{array}{c}163(67,9) \\
20(8,3) \\
12(5)\end{array}$ & $\begin{array}{l}18(7,5) \\
3(1,2) \\
1(0,4)\end{array}$ & $\begin{array}{l}15(6,2) \\
2(0,8) \\
0\end{array}$ & 0,182 \\
\hline
\end{tabular}


Revista Brasileira da Educação Profissional e Tecnológica, v. 1, n. 20, e10874, 2021, p. 8 de 17 CC BY 4.0 | ISSN 2447-1801 | DOI: https://doi.org/10.15628/rbept.2021.10874

\begin{tabular}{|c|c|c|c|c|c|}
\hline & Outra & $4(1,6)$ & $2(0,8)$ & 0 & \\
\hline $\begin{array}{l}\text { Município de } \\
\text { residência }\end{array}$ & $\begin{array}{l}\text { Mesmo do curso } \\
\text { Outro município }\end{array}$ & $\begin{array}{l}136(56,7) \\
63(26,2)\end{array}$ & $\begin{array}{l}18(7,5) \\
6(2,5)\end{array}$ & $\begin{array}{c}11(4,6) \\
6(2,5)\end{array}$ & 0,748 \\
\hline $\begin{array}{l}\text { Onde fez/faz o Técnico } \\
\text { em Enfermagem }\end{array}$ & $\begin{array}{l}\text { Instituição da } \\
\text { especialização } \\
\text { Outras instituições }\end{array}$ & $\begin{array}{c}96(40,2) \\
102(42,6)\end{array}$ & $\begin{array}{l}7(2,9) \\
17(7,1)\end{array}$ & $\begin{array}{l}10(4,2) \\
7(2,9)\end{array}$ & 0,088 \\
\hline $\begin{array}{l}\text { Ano de conclusão do } \\
\text { curso }\end{array}$ & $\begin{array}{l}2019 \\
2020\end{array}$ & $\begin{array}{l}26(10,8) \\
2(0,8)\end{array}$ & $\begin{array}{l}0 \\
0\end{array}$ & $\begin{array}{c}0 \\
1(0,4)\end{array}$ & 0,056 \\
\hline Trabalha & $\begin{array}{l}\text { Sim } \\
\text { Não }\end{array}$ & $\begin{array}{c}178(74,2) \\
21(8,8)\end{array}$ & $\begin{array}{l}21(8,8) \\
3(1,2)\end{array}$ & $\begin{array}{l}15(6,2) \\
2(0,8)\end{array}$ & 0,951 \\
\hline $\begin{array}{l}\text { Atua como Técnico de } \\
\text { Enfermagem }\end{array}$ & $\begin{array}{l}\text { Sim } \\
\text { Não }\end{array}$ & $\begin{array}{c}146(60,8) \\
20(8,3)\end{array}$ & $\begin{array}{l}19(7,9) \\
2(0,8)\end{array}$ & $\begin{array}{l}9(3,8) \\
6(2,5)\end{array}$ & $0,003^{*}$ \\
\hline $\begin{array}{l}\text { Local de trabalho } \\
\text { como Técnico de } \\
\text { Enfermagem }\end{array}$ & $\begin{array}{l}\text { Atendimento domiciliar } \\
\text { Clínica de hemodiálise } \\
\text { ILPI } \\
\text { Hospital } \\
\text { Policlínica } \\
\text { SAMU } \\
\text { UBS } \\
\text { UPA }\end{array}$ & $\begin{array}{c}2(0,8) \\
15(6,2) \\
9(3,8) \\
78(32,5) \\
8(3,3) \\
1(0,4) \\
19(7,9) \\
14(5,8)\end{array}$ & $\begin{array}{c}0 \\
2(0,8) \\
0 \\
14(5,8) \\
1(0,4) \\
0 \\
0 \\
2(0,8)\end{array}$ & $\begin{array}{c}0 \\
2(0,8) \\
0 \\
5(2,1) \\
0 \\
0 \\
1(0,4) \\
1(0,4)\end{array}$ & 0,786 \\
\hline Regime de trabalho & $\begin{array}{l}12 \times 36 \text { horas } \\
\text { Diarista } \\
\text { Outro }\end{array}$ & $\begin{array}{c}98(43,4) \\
60(26,5) \\
9(4)\end{array}$ & $\begin{array}{c}17(7,5) \\
4(1,8) \\
0\end{array}$ & $\begin{array}{c}7(3,1) \\
5(2,2) \\
0\end{array}$ & 0,528 \\
\hline Turno de trabalho & $\begin{array}{l}\text { Diurno } \\
\text { Noturno } \\
\text { Ambos }\end{array}$ & $\begin{array}{c}133(57,8) \\
34(14,8) \\
3(1,3)\end{array}$ & $\begin{array}{c}14(6,1) \\
7(3) \\
0\end{array}$ & $\begin{array}{c}10(4,3) \\
3(1,3) \\
0\end{array}$ & 0,861 \\
\hline
\end{tabular}

Notas: $\%=$ nos parênteses, percentual relativo ao total de respostas em cada variável; ${ }^{*}=p<0,05$.

Fonte: Elaborado pelas autoras.

Verificou-se que não houve diferença significativa estatisticamente entre os gêneros dos participantes interessados no curso, indicando que pessoas de ambos os gêneros gostariam de fazê-lo. O estado civil seguiu o mesmo caminho, apontando que essa variável também não interferiu no interesse pelo curso, ou seja, pessoas de estados civis diversos se interessaram na Especialização Técnica em Saúde do Idoso.

Em relação à escolaridade, fato parecido ocorreu, entretanto, destacaram-se os participantes que possuíam o nível médio como os mais interessados, pois eram os que atuavam como técnicos(as) de enfermagem. Em contrapartida, pôde-se verificar que participantes com outros níveis de escolaridade também se interessaram pela especialização. Outro dado relevante foi o fato de que tanto respondentes que moravam na cidade da instituição que ofertará a especialização quanto em outros municípios da região se interessaram pelo curso, ou seja, a distância de deslocamento não seria um empecilho para fazê-lo.

Mediante esta conjuntura, voltando à realidade local do cenário desta proposta de curso, constata-se que, em 2019, o município possuía uma população estimada de 90.082 habitantes (IBGE, 2020). No ano de 2010, havia 6.401 idosos entre 60 e 74 anos e, seguindo a tendência de crescimento, em 2018 havia 11.251 indivíduos na mesma faixa etária, um aumento expressivo de 75,77\% (FIOCRUZ, 2020). Em outra análise, foi empregado o índice de envelhecimento utilizado internacionalmente em estudos demográficos, que compara a população acima de 65 anos com a população menor de 15 anos, e obteve-se o apontamento de que 0 município possuía uma população considerada envelhecida (PMSJDR, 2014).

É importante destacar que a taxa de envelhecimento é a razão entre a população de 65 anos ou mais em relação à população total. Entre 2000 e 2010, a 
taxa de envelhecimento do município passou de 7,56\% para 9,38\%. Em 1991, era 6,26\%. Em Minas Gerais, no mesmo período, a taxa de envelhecimento passou de $4,83 \%$ (1991), para 5,83\% (2000) e para 7,36\% (2010). Percebe-se que essa taxa municipal foi superior à estadual (PNUD; IPEA; FJP, 2020).

O município possui uma significativa rede de atenção à saúde, com 68 estabelecimentos credenciados ao SUS, contando com serviços como 20 unidades básicas de saúde, dois hospitais gerais, duas policlínicas de saúde, uma Unidade de Pronto Atendimento (UPA), o Serviço de Atendimento Móvel de Urgência (SAMU) e uma ILPI, os quais seriam possíveis cenários de trabalho ao profissional formado na Especialização Técnica em Saúde do Idoso (CNES, 2020).

A instituição de ensino onde os participantes cursaram/estavam cursando o curso Técnico em Enfermagem também não apresentou significativo peso estatístico. Assim, tanto egressos da instituição quanto de outras se interessaram pelo curso, o que é um indicativo de demanda importante. Isso também comprovou que o curso é bem aceito também por técnicos de enfermagem egressos de outras instituições de ensino. Outro ponto de destaque é que a expressiva maioria dos estudantes do curso Técnico em Enfermagem (96,6\%) se interessou pelo curso. Nenhum o rejeitou. Nesse sentido, é possível considerar que essa grande intenção dos egressos em realizar a especialização poderá se repetir ano após ano.

No que tange às características ocupacionais, a análise da variável "trabalho" indicou que tanto pessoas que trabalhavam como técnicos(as) de enfermagem ou em outras áreas, quanto as pessoas que não trabalhavam gostariam de fazer o curso. Ressalta-se que a maioria das pessoas que trabalhava indicou a resposta "sim" e algumas responderam que o curso seria um diferencial em seu currículo. Os participantes que atuavam como técnicos foram os mais interessados. A baixa rejeição por essa parcela da amostra é um relevante indicativo de sua demanda. Entretanto, pessoas que trabalhavam em outras áreas também gostariam de fazer o curso. Já as que não trabalhavam poderiam considerá-lo como uma possibilidade de capacitação para retorno/inserção no mercado de trabalho em Enfermagem.

Percebeu-se que a especialização se mostrou interessante para técnicos(as) de enfermagem que atuavam em diferentes instituições e também em domicílio, o que é um indicativo da importância do curso para esses profissionais. Os técnicos que exerciam diferentes regimes de trabalho e em horários variados gostariam de fazer essa especialização. Como mencionado, a população brasileira está envelhecendo e, cada vez mais, idosos serão atendidos por esses profissionais ou poderão ir morar nas ILPIs, o que exigirá trabalhadores cada vez mais capacitados para atenderem às especificidades dessa parcela da população.

A população idosa apresenta demandas de saúde específicas em relação aos demais grupos etários e precisa dos serviços de saúde com mais frequência por um período longo de tempo. Nesse sentido, profissionais de Enfermagem devem estar aptos a desenvolverem atitudes efetivas e de impacto na atenção à saúde desse grupo populacional nos mais diversos cenários de atuação (PROCHET et al., 2012).

Os dados apontaram que $41,2 \%$ dos participantes atuavam em instituições hospitalares e $4,4 \%$ atuavam em ILPIs. Ainda que houvesse esse menor quantitativo da amostra atuando nessas instituições pelo reduzido número de ILPIs disponíveis, é relevante destacar ser significativo o quantitativo de idosos atendidos nas diversas instituições de saúde em decorrência do envelhecimento da população e suas 
consequentes limitações e/ou agravos que requerem atendimento de saúde. Percebeu-se que a especialização era interessante para técnicos de enfermagem que atuavam em diferentes instituições e também em domicílio, o que se mostrou um considerável indicativo da importância do curso para esses profissionais.

Silva e colaboradores (2017) apontaram que idosos com limitações funcionais realizavam mais consultas médicas e eram mais propensos à ocorrência de hospitalizações, independentemente de fatores predisponentes, como idade e sexo, assim como de características facilitadoras, como residência com 0 cônjuge/companheiro(a) e nível de escolaridade. Foram observadas fortes associações entre limitação funcional e maior número de consultas médicas e ocorrência de uma ou mais hospitalizações. Tais evidências levaram a concluir que os idosos buscavam tanto unidades de atenção básica e especializadas para consulta, como necessitavam do atendimento hospitalar.

Entendeu-se que capacitar e especializar o técnico de enfermagem que atua no cuidado hospitalar e em outros cenários de saúde para o cuidado a idosos ia ao encontro de suprir atuais e futuras demandas do mercado de trabalho em Enfermagem. Os objetivos tangem à melhoria da qualidade da assistência nos serviços de saúde públicos e privados, voltada ao atendimento dos idosos e um ensino de Enfermagem que valorize não somente o cuidar da saúde do idoso no ambiente hospitalar, mas também nos diversos espaços onde convivem.

A seguir, é apresentado o cruzamento das variáveis "interesse na área de cuidados com a pessoa idosa" e "interesse em fazer a Especialização Técnica em Saúde do Idoso" (Gráfico 3). Como era de se esperar, a relação entre ambas foi muito expressiva estatisticamente $(p=0,000)$. Destaca-se 0 grande interesse dos participantes pela área, provavelmente refletindo as mudanças demográficas e epidemiológicas que estão ocorrendo na população e as demandas atuais do mercado de trabalho em Enfermagem. 
Gráfico 3: Relação entre as variáveis "interesse na área de cuidados com a pessoa idosa" e "interesse em fazer a Especialização Técnica em Saúde do Idoso" (N = 240).

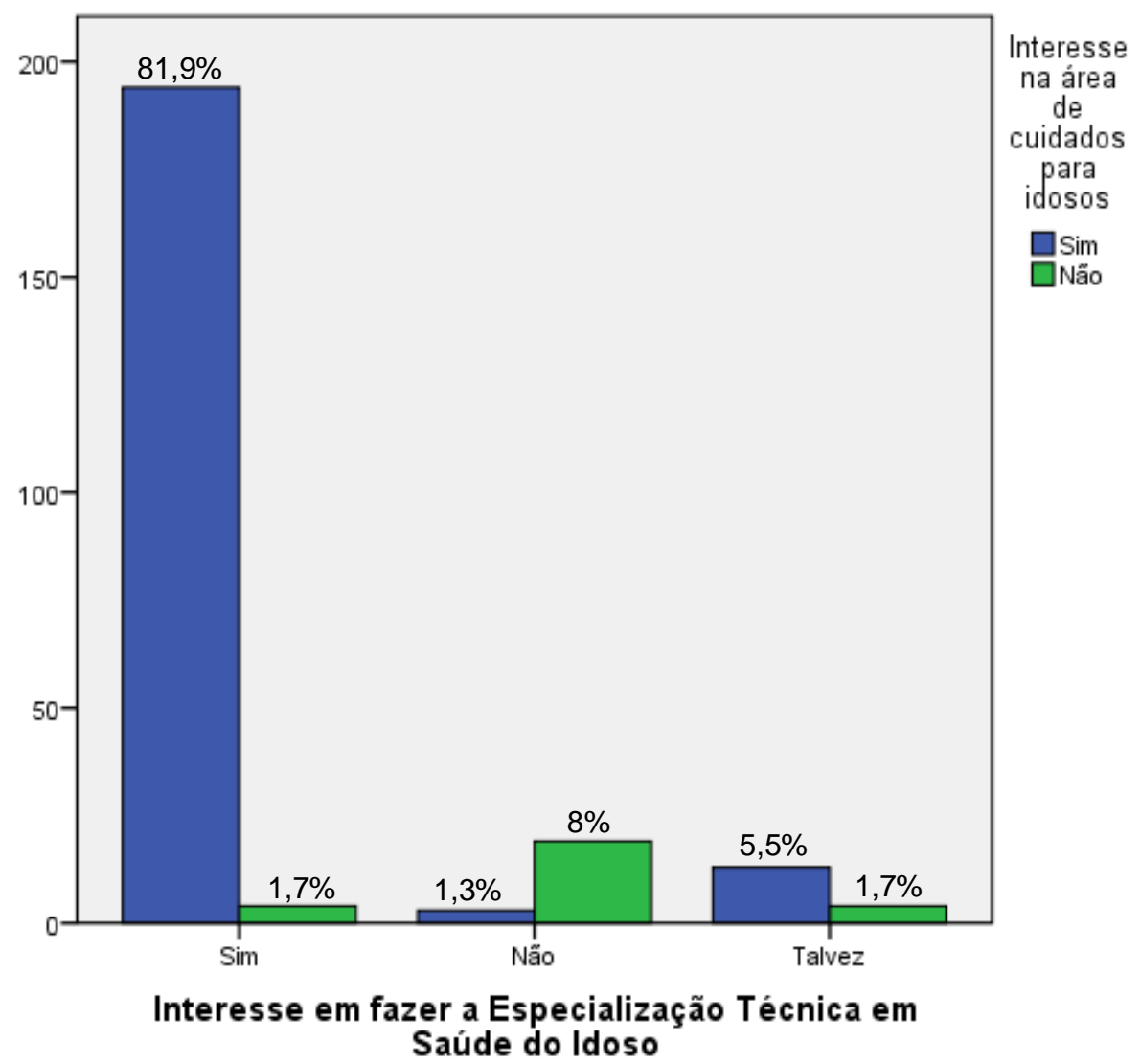

Fonte: Elaborado pelas autoras. São João del-Rei, 2020.

A variável "considera o campo de trabalho em saúde do idoso promissor" foi cruzada com a variável "interesse em fazer a Especialização Técnica em Saúde do Idoso" (Gráfico 4). Verificou-se que as variáveis também tiveram uma relação estatisticamente significante $(p=0,038)$. Ressalta-se que, mesmo as pessoas que responderam que não fariam ou que talvez fariam o curso consideraram essa área promissora, o que é uma informação substancial para o curso. Mais uma vez, mostra que tais pessoas poderiam vir a fazer a especialização no futuro. 
Gráfico 4: Relação entre as variáveis "considera o campo de trabalho em saúde do idoso promissor" e "interesse em fazer a Especialização Técnica em Saúde do Idoso" ( $\mathrm{N}=240)$.

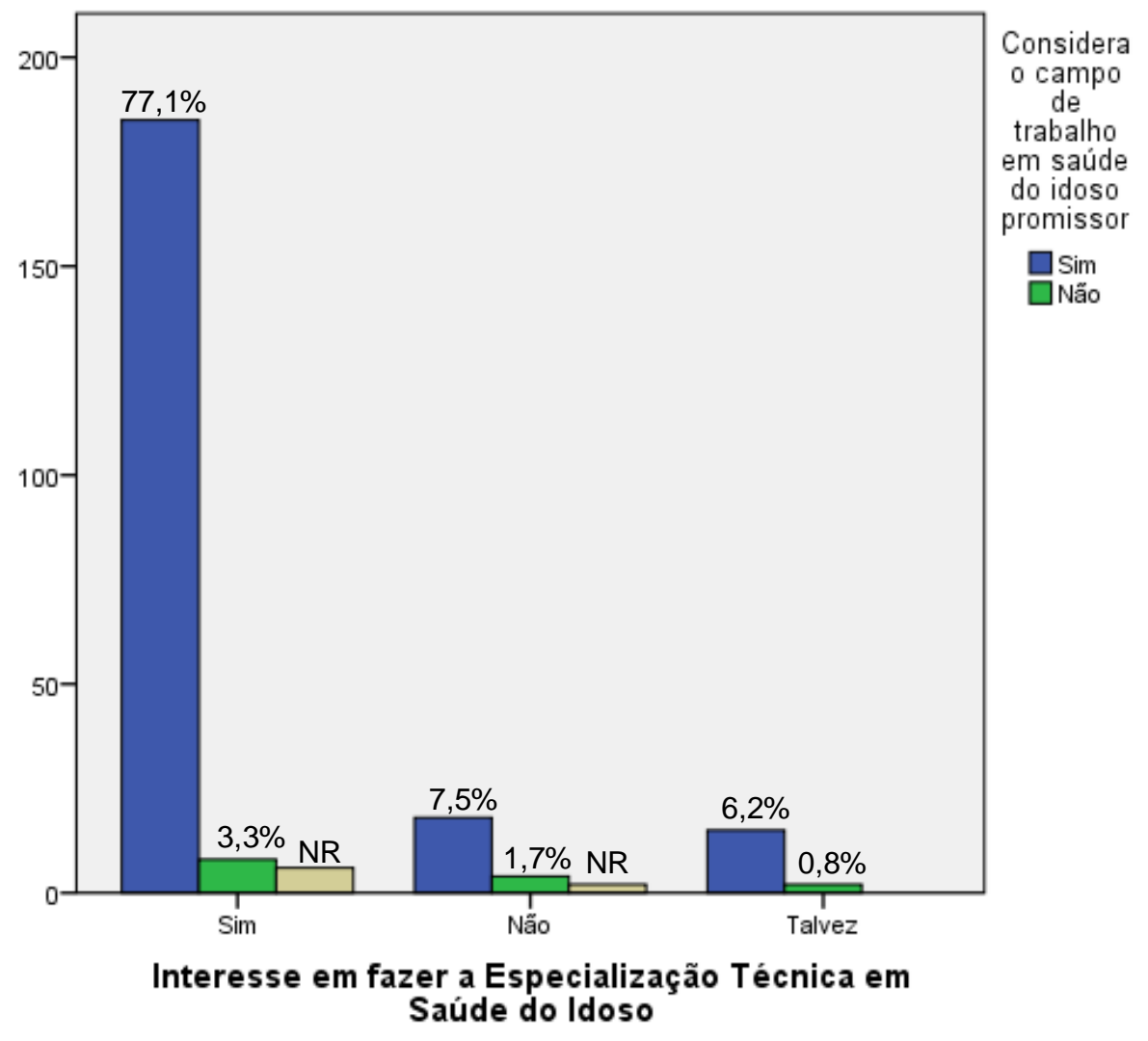

Nota: NR = não responderam. Fonte:

Elaborado pelas autoras. São João del-Rei, 2020.

Esta análise reforça o fato de que, nas instituições de saúde, a melhoria da qualificação dos trabalhadores de Enfermagem e sua profissionalização trazem benefícios para o cuidado, para as organizações e para os próprios trabalhadores. Além disso, os estabelecimentos de saúde são mais bem avaliados tanto pelos clientes quanto pelos trabalhadores. Especializar-se e qualificar-se interfere no desenvolvimento profissional. Entre trabalhadores de Enfermagem, a profissionalização relaciona-se a melhores remunerações, mais satisfação no emprego e realização pessoal (FURUKAWA; CUNHA, 2010).

\subsection{MELHOR FORMA DE OFERTAR A ESPECIALIZAÇÃO TÉCNICA EM SAÚDE DO IDOSO}

Neste estudo de demanda, os participantes responderam a perguntas relativas à melhor maneira de ofertar a especialização. Tais perguntas foram respondidas somente por aqueles que apresentaram algum interesse em realizar 0 curso, ou, seja, que responderam "sim" ou "talvez" quando perguntados se participariam $(n=216 ; 90,0 \%)$. Conhecer as preferências acerca da melhor forma de organização do curso é importante para o seu planejamento. É fundamental para a 
permanência do discente no curso, reduzindo a evasão e aumentando a taxa de conclusão. A Tabela 2 apresenta os resultados dos cruzamentos das variáveis.

Tabela 2: Análise da relação entre as variáveis relativas à oferta do curso e o interesse pela Especialização Técnica em Saúde do Idoso $(\mathrm{N}=216)$.

\begin{tabular}{|c|c|c|c|c|}
\hline \multirow[t]{2}{*}{ Variáveis } & \multirow[t]{2}{*}{ Categorias } & \multicolumn{2}{|c|}{ Percentual de Interesse } & \multirow[b]{2}{*}{$p$} \\
\hline & & Sim & Talvez & \\
\hline $\begin{array}{l}\text { Horário das } \\
\text { aulas } \\
\text { teóricas }\end{array}$ & $\begin{array}{l}\text { Manhã } \\
\text { Tarde } \\
\text { Noite }\end{array}$ & $\begin{array}{c}9(4,5) \\
20(10) \\
165(82,5)\end{array}$ & $\begin{array}{l}1(0,5) \\
1(0,5) \\
12(6)\end{array}$ & $0,000^{*}$ \\
\hline $\begin{array}{l}\text { Horário do } \\
\text { estágio }\end{array}$ & $\begin{array}{l}\text { Manhã } \\
\text { Tarde } \\
\text { Manhã e tarde }\end{array}$ & $\begin{array}{c}122(61) \\
74(37) \\
1(0,5)\end{array}$ & $\begin{array}{l}9(4,2) \\
5(2,5) \\
3(1,5)\end{array}$ & $0,000^{*}$ \\
\hline $\begin{array}{l}\text { Frequência } \\
\text { do estágio }\end{array}$ & $\begin{array}{l}\text { Uma vez/semana } \\
\text { Duas vezes/semana }\end{array}$ & $\begin{array}{c}82(41) \\
116(58)\end{array}$ & $\begin{array}{l}8(4) \\
6(3)\end{array}$ & $0,000^{*}$ \\
\hline
\end{tabular}

Notas: $\%=$ nos parênteses, percentual relativo ao total de respostas em cada variável; ${ }^{*}=p<0,05$.

Fonte: Elaborado pelas autoras. São João del-Rei, 2020.

Os resultados relativos ao melhor turno para oferta do curso - aulas teóricas - refletem a realidade do maior público que possivelmente fará o curso, a saber, os trabalhadores que atuam, em sua maior parte, no período diurno. Não foi dada a possibilidade de escolha do estágio noturno porque, nesse horário, muitas vezes, os idosos estarão dormindo ou as instituições concedentes estarão fechadas, não havendo como realizar essa atividade no período da noite.

Entretanto, é digno de nota o fato de que a Coordenação do Curso poderia adequar a oferta de estágio de acordo com as especificidades de cada discente. Essa possibilidade é fundamental para a permanência no curso, reduzindo a evasão e aumentando a taxa de conclusão. A maior preferência de que o estágio seja ofertado duas vezes por semana talvez represente um reflexo do fato de a maior parte dos interessados trabalhar no período diurno, assim, se o estágio ocorrer duas vezes por semana, será mais fácil conciliá-lo com a atividade profissional, pois será finalizado em um período de tempo menor.

\section{CONSIDERAÇÕES FINAIS}

O estudo de demanda apontou uma aceitação consistente da Especialização Técnica em Saúde do Idoso dentre os participantes. O potencial público interessado no curso tem idades variadas, tanto do gênero masculino quanto feminino, conforme declarado neste estudo pelos participantes, com variados estados civis e tempos de profissão e mora tanto na cidade onde o curso será ofertado quanto em outros municípios da região. A maioria possui o nível médio, é egresso/estudante de diferentes instituições de ensino, trabalha como técnico de enfermagem em distintos serviços de saúde e também em domicílio, principalmente no período diurno e em diferentes regimes de trabalho, se interessa pela área de cuidados com a pessoa 
idosa e considera esse campo de trabalho promissor. Prefere que o curso seja ofertado no período noturno e que o estágio ocorra de manhã, duas vezes por semana.

A análise dos resultados da pesquisa sobre a demanda do curso embasou a sua proposição, assim como o delineamento do Projeto Pedagógico do Curso. Os parâmetros advindos desse perfil de demanda e o mundo do trabalho voltado a idosos balizaram os processos de planejamento de um curso de Especialização Técnica em Saúde do Idoso, com adequação e dimensionamento da oferta formativa de conteúdos de formação profissionalizante direcionados ao envelhecimento.

Compreende-se que o profissional capacitado em Saúde do Idoso poderá obter competências e habilidades para se inserir em todos os níveis de atenção à saúde do idoso, para atuar nos setores público ou privado, considerando os diversos cenários da prática. Dessa forma, o Técnico de Enfermagem Especialista em Saúde do Idoso será capaz de atender, juntamente com o Enfermeiro, pessoas idosas nos mais diferentes contextos, como hospitais, serviços de urgência e emergência, empresas de assistência domiciliar (home care), ILPIs, asilos e casas de repouso, dentre outras instituições.

A proposição do curso teve como horizonte, além da formação de profissionais especialistas, a melhoraria da qualidade de vida de idosos, que receberão um cuidado de Enfermagem mais qualificado e específico para as suas necessidades. É necessária uma formação profissional que vise à integralidade da assistência e ao comprometimento social, aliado à formação humana e ética de Especialistas Técnicos em Saúde do Idoso.

\section{REFERÊNCIAS}

BRASIL. Lei no 7.498 de 25 de junho de 1986. Dispõe sobre a regulamentação do exercício da enfermagem, e dá outras providências. Diário Oficial [da] República Federativa do Brasil, Brasília, 25 jun 1986. Seção 1, p. 9275-9279. Disponível em: <http://www.planalto.gov.br/ccivil_03/LEIS/L7498.htm>. Acesso em: 01 jun. 2020.

BRASIL. Ministério da Educação. Catálogo Nacional de Cursos Técnicos. 3. ed. Brasília: Ministério da Educação, 2017. Disponível em:

<http://portal.mec.gov.br/docman/novembro-2017-pdf/77451-cnct-3a-edicao-pdf1/file>. Acesso em: 01 jul. 2020.

BRASIL. Ministério da Saúde. Cadastro Nacional de Estabelecimentos de Saúde (CNES). Brasília: Ministério da Saúde, 2020. Disponível em: <http://cnes2.datasus.gov.br/Lista_Es_Municipio.asp?VEstado=31\&VCodMunicipio= 316250\&NomeEstado=MINAS\%20GERAIS >. Acesso em: 03 jun. 2020.

BRASIL. Ministério da Saúde. Comissão Nacional de Ética em Pesquisa. Resolução no 510, de 07 de abril de 2016. Dispõe sobre as normas aplicáveis a pesquisas em Ciências Humanas e Sociais. Diário Oficial [da] República Federativa do Brasil, Brasília, DF, 24 maio 2016. Disponível em: <http://conselho.saude.gov.br/resolucoes/2016/Reso510.pdf>. Acesso em: 02 jun. 2020. 
BRASIL. Ministério da Saúde. Portaria no 2.528 de 19 de outubro de 2006. Dispõe sobre Política Nacional de Saúde da pessoa idosa. Diário Oficial [da] República Federativa do Brasil, Brasília, 2006. Disponível em:

<http://bvsms.saude.gov.br/bvs/saudelegis/gm/2006/prt2528_19_10_2006.html>. Acesso em: 11. jun. 2020.

BRASIL. Ministério da Saúde. Saúde da pessoa idosa: prevenção e promoção à saúde integral. Brasília: Ministério da Saúde, 2019. Disponível em:

$<$ https://saude.gov.br/saude-de-a-z/saude-da-pessoa-idosa>. Acesso em $11 \mathrm{dez}$. 2019.

FUNDAÇÃO OSWALDO CRUZ (FIOCRUZ). Sistema de Indicadores de Saúde e Acompanhamento de Políticas do Idoso (SIAPE-IDOSO). Rio de Janeiro:

FIOCRUZ, 2020. Disponível em: <https://sisapidoso.icict.fiocruz.br/consulta-pormunicipio>. Acesso em: 03 jun. 2020.

INSTITUTO BRASILEIRO DE GEOGRAFIA E ESTATÍSTICA (IBGE). São João delRei. Rio de Janeiro: IBGE, 2020. Disponível em:

$<$ https://cidades.ibge.gov.br/brasil/mg/sao-joao-del-

rei/pesquisa/23/24304?detalhes=true>. Acesso em: 03 jun. 2020.

INSTITUTO BRASILEIRO DE GEOGRAFIA E ESTATÍSTICA (IBGE). Síntese de indicadores sociais: uma análise das condições de vida da população brasileira: 2016. Rio de Janeiro: IBGE, 2016. 146 p. Disponível em:

$<$ https://biblioteca.ibge.gov.br/visualizacao/livros/liv98965.pdf>. Acesso em: 03 jun. 2020.

CONSELHO FEDERAL DE ENFERMAGEM (COFEN). Enfermagem em Números. Brasília: COFEN, 2020. Disponível em: <http://www.cofen.gov.br/enfermagem-emnumeros>. Acesso em: 03 jun. 2020.

FURUKAWA, P. O.; CUNHA, I. C. K. O. Da gestão por competências às competências gerenciais do enfermeiro. Rev Bras Enferm., v. 63, n. 6, p. 10611066, 2010.

LEVIN, J; FOX, A.; FORDE, D. R. Estatística para ciências humanas. 12. ed. Belo Horizonte: Pearson, 2012.

MALAGUTTI, W.; MIRANDA, S. M. R. C. Os caminhos da enfermagem: de Florence à globalização. Enferm Foco, v. 2, (Supl), p. 85-88. 2011.

ORGANIZAÇÃO MUNDIAL DA SAÚDE (OMS). Organização Pan-americana da Saúde (OPAS Brasil). Folha informativa - Envelhecimento e saúde. Brasília: OMS/OPAS Brasil, 2018. Disponível em:

$<$ https://www.paho.org/bra/index.php?option=com_content\&view=article\&id=5661:fol ha-informativa-envelhecimento-e-saude\&ltemid=820 . Acesso em: 03 jun. 2020.

PREFEITURA MUNICIPAL DE SÃO JOÃO DEL-REI (PMSJDR). Secretaria de Governo. Anexo I. Projeto Básico. Termo de Referência. São João del-Rei: PMSJDR, 2014.

PROCHET, T. C.; SILVA, M. J. P. Percepção do idoso dos comportamentos afetivos expressos pela equipe de enfermagem. Esc Anna Nery Rev Enferm., v. 15, n. 4, p. 784-790, 2011.

PROGRAMA DAS NAÇÕES UNIDAS PARA DESENVOLVIMENTO; FUNDAÇÃO JOÃO PINHEIRO; INSTITUTO DE PESQUISA ECONÔMICA APLICADA (PNUD; 
IPEA; FJP). Atlas do Desenvolvimento Humano no Brasil. São João del-Rei, MG. Disponível em: <http://www.atlasbrasil.org.br/2013/pt/perfil_m/sao-joao-delrei_mg\#demografia>. Acesso 20 mai. 2020.

RIBEIRO, G. K. N. A.; IWAMOTO et al. Nursing Professionals Trained for the Labor Market in The State of Minas Gerais. Rev Min Enferm., v. 18, n. 1, p. 21-26, 2014. DOI: http://www.dx.doi.org/10.5935/1415-2762.20140002.

\section{SELLTIZ, C.; WRIGHTSMAN, L. S.; COOK, S. W. Métodos de pesquisa nas} relações sociais: v. 2. 2. ed. São Paulo: EPU, 2006.

SILVA, A. M. M. et al. Uso de serviços de saúde por idosos brasileiros com e sem limitação funcional. Rev Saúde Pública., v. 51, Supl 1:5s, 2017.

https://doi.org/10.1590/s1518-8787.2017051000243.

\section{Anexo A:}

\section{Levantamento de demanda para criação do curso de Especialização Técnica em Saúde do Idoso}

\section{Prezado(a),}

Este é um estudo de viabilidade para implantação do curso de Especialização Técnica em Saúde do Idoso. Trata-se de um curso curto, que será ofertado em um semestre e é destinado para Técnicos de Enfermagem.

Iniciais:

1. Idade:

2. Gênero:

( ) Masculino ( ) Feminino ( ) Outro:

3. Estado civil:

( ) Solteiro(a) ( ) Casado(a) ( ) Separado(a) ou divorciado(a) ( ) Viúvo(a)

4. Qual o seu nível de escolaridade?

( ) Ensino médio completo ( ) Superior completo ( ) Superior incompleto

( ) Pós-Graduação ( ) Outro:

5. Município de residência:

6. Em qual instituição você concluiu/está cursando o curso Técnico em Enfermagem?

7. Se já concluiu, há quanto tempo você concluiu o curso Técnico em Enfermagem (em anos e meses)?

8. Se está estudando, quando concluirá o curso Técnico em Enfermagem?

9. Você trabalha?

( ) Sim ( ) Não 
10. Se você trabalha, atua como Técnico de Enfermagem?

( ) Não ( ) Sim. Local de trabalho/cidade:

11. Se você trabalha, qual é seu regime de trabalho?

( ) $12 \times 36$ horas ( ) Diarista ( ) Outro:

12. Se você trabalha, qual é o seu turno de trabalho?

( ) Diurno ( ) Noturno

13. Você tem interesse na área de cuidados com a pessoa idosa?

( ) Sim ( ) Não

14. Você acha o campo de trabalho em saúde do idoso promissor?

( ) $\operatorname{Sim}($ ) Não

15. Você teria interesse em fazer gratuitamente o Curso de Especialização Técnica em Saúde do Idoso, com duração de um semestre?

( ) Sim ( ) Não ( ) Talvez

Por que?

16. Se você tiver interesse, qual o melhor horário para oferta do curso?

( ) De manhã ( ) À tarde ( ) À noite

17. No curso de Especialização Técnica em Saúde do Idoso, será ofertado estágio em instituições de saúde. Qual o melhor horário para fazê-lo?

( ) De manhã ( ) À tarde

18. Com qual frequência?

( ) Uma vez por semana ( ) Duas vezes por semana 